\title{
Mental health consequences of urban air pollution: prospective population-based longitudinal survey
}

\author{
Ioannis Bakolis ${ }^{1,2}\left(\right.$ Ryan Hammoud $^{3} \cdot$ Robert Stewart $^{4,5} \cdot$ Sean Beevers ${ }^{6} \cdot$ David Dajnak $^{6} \cdot$ Shirlee MacCrimmon $^{4}$. \\ Matthew Broadbent ${ }^{5} \cdot$ Megan Pritchard $^{5} \cdot$ Narushige Shiode $^{7}$. Daniela Fecht ${ }^{8}$. John Gulliver ${ }^{9}$. Matthew Hotopf ${ }^{4,5}$. \\ Stephani L. Hatch ${ }^{4,5} \cdot \operatorname{lan}$ S. Mudway ${ }^{6,10}$
}

Received: 4 December 2019 / Accepted: 23 September 2020 / Published online: 24 October 2020

(c) The Author(s) 2020

\begin{abstract}
Purpose The World Health Organisation (WHO) recently ranked air pollution as the major environmental cause of premature death. However, the significant potential health and societal costs of poor mental health in relation to air quality are not represented in the WHO report due to limited evidence. We aimed to test the hypothesis that long-term exposure to air pollution is associated with poor mental health.

Methods A prospective longitudinal population-based mental health survey was conducted of 1698 adults living in 1075 households in South East London, from 2008 to 2013. High-resolution quarterly average air pollution concentrations of nitrogen dioxide $\left(\mathrm{NO}_{2}\right)$ and oxides $\left(\mathrm{NO}_{x}\right)$, ozone $\left(\mathrm{O}_{3}\right)$, particulate matter with an aerodynamic diameter $<10 \mu \mathrm{m}\left(\mathrm{PM}_{10}\right)$ and $<2.5 \mu \mathrm{m}\left(\mathrm{PM}_{2.5}\right)$ were linked to the home addresses of the study participants. Associations with mental health were analysed with the use of multilevel generalised linear models, after adjusting for large number of confounders, including the individuals' socioeconomic position and exposure to road-traffic noise.

Results We found robust evidence for interquartile range increases in $\mathrm{PM}_{2.5}, \mathrm{NO}_{x}$ and $\mathrm{NO}_{2}$ to be associated with 18-39\% increased odds of common mental disorders, $19-30 \%$ increased odds of poor physical symptoms and 33\% of psychotic experiences only for $\mathrm{PM}_{10}$. These longitudinal associations were more pronounced in the subset of non-movers for $\mathrm{NO}_{2}$ and $\mathrm{NO}_{x}$. Conclusions The findings suggest that traffic-related air pollution is adversely affecting mental health. Whilst causation cannot be proved, this work suggests substantial morbidity from mental disorders could be avoided with improved air quality.
\end{abstract}

Keywords Mixed models $\cdot$ Air quality $\cdot$ Common mental disorders $\cdot$ Psychotic experiences $\cdot$ Urban health

\section{Introduction}

The Organization for Economic Co-operation and Development (OECD) [1] and World Health Organisation (WHO) [2] rank air pollution as the major environmental cause of premature death and have concluded that by reducing air pollution levels, countries can alleviate the burden of disease by a net benefit of US\$135,371 million [3]. These estimates are based on the established associations between short- and long-term air pollution exposures

Electronic supplementary material The online version of this article (https://doi.org/10.1007/s00127-020-01966-x) contains supplementary material, which is available to authorized users.

Ioannis Bakolis

ioannis.bakolis@kcl.ac.uk

Extended author information available on the last page of the article and adverse cardiopulmonary morbidity and mortality, but there is now increasing evidence suggesting impacts on neurological endpoints, with an increased focus on pollutants derived from transport sources [4-10]. Observational studies conducted globally have now linked traffic derived air pollution exposures with increased risk of dementia [11], autism spectrum disorders [5], psychotic disorders $[6,7,9,10]$, schizophrenia [12], depression [13], anxiety [14] and cognitive impairment [8] and potential causal pathways have been suggested [15-19]. Specifically, a recent systematic review presented biologically plausible effects of traffic related pollution on cognition with the use of neuroimaging data [20]. These neurological impacts imply significant additional economic and societal costs not currently represented in the WHO [2] and OECD [1] assessments and must be viewed against the reality that the majority of world's urban populations still breathes air 
failing to meet the health-based WHO Air Quality Guidelines, especially for $\mathrm{PM}_{2.5}$ [21].

Findings from population-based studies of mental health are often limited by: (1) the simplicity of brief screening instruments or proxy measures (e.g. prescription of medication) [7]; (2) over-simplified estimates and surrogates of air pollution measures (e.g. proximity to major roads) [4] or air pollution indices that lack sufficient resolution to capture exposures that vary dramatically over fine spatial scales [9]; (3) cross-sectional designs which fail to measure cumulative exposures and reduce the possibility of reverse causation [10]; (4) failure to measure longitudinal exposures to a range of air pollutants from multiple sources [12] and (5) inadequate control of potential confounders, especially in relation to indices of urbanisation and deprivation (e.g. communities of low socioeconomic status tend to live close to heavy traffic) $[8,22]$. Thus, rigorous methodology to confirm the current evidence base is needed [23].

Against this background, we aimed to address the gaps within the existing literature and examine, within a large urban population, the hypothesis that long-term residential exposure to urban air pollution, in an inner-city London area of high-traffic flows is associated with increased risk of common mental disorders, psychotic experiences and symptoms indicative of mental distress, after controlling for large number of confounders, including individuals' socioeconomic position and exposure to urban noise.

\section{Methods}

\section{Study area and population}

The South East London Community Health (SELCoH) study is a UK psychiatric and physical morbidity survey of 1698 adults aged 16 years and over residing in 1075 randomly selected households in the boroughs of Southwark and Lambeth between 2008 and 2010, which comprise a total population of 638,200 (mid-2017 estimates) (Fig. 1 and Figure S1). Following the baseline survey (SELCoH 1), 1596 (94\%) participants agreed to be re-contacted from 2011 to 2013 and 1052 (73\% response rate) participants were re-interviewed (SELCoH 2). The demographic and socioeconomic profiles of the overall sample was similar to the 2011 UK Census demographic and socioeconomic indicators for the catchment area. Details of ethics, study design, geocoding information, sampling techniques, participants, procedures and measures have been published elsewhere [24, 25].

\section{Measures}

At all SELCoH examinations (SELCoH 1 and 2), common mental disorder (CMD) was assessed by the Revised Clinical Interview Schedule (CIS-R), a structured interview administered by trained staff that asks about 14 symptom domains (e.g. fatigue, sleep problems, irritability) [26]. The 14 sub-scale scores are summed to create an overall CIS-R psychological morbidity total score. A conventional CIS-R total score of 12 or more is used to indicate the presence of a CMD [26]. Physical symptoms were measured using the Patient Health Questionnaire subscale (PHQ-15). PHQ15 screens for 15 somatic symptoms that account for more than $90 \%$ of the physical complaints reported in the outpatient setting and has been strongly associated with mental disorders and extensively used in psychiatric research [27]. A total score was acquired by summing all the items in the questionnaire, which was further categorised (0-4, Minimal; 5-9: Low; 10-14; Medium; 15-30: High), due to the skewness of the distribution of the total score. Higher scores indicated more severe symptoms. Fair or poor general health was indicated by a self-rated general health question from the 12-item Short Form (SF-12) questionnaire [28]. We assessed subclinical psychotic experiences using the Psychosis Screening Questionnaire (PSQ) [29], but only within the SELCoH 1 survey, as the questionnaire was not administered in SELCoH 2. Following previous studies that looked at psychotic experiences alone, we excluded question domains related to hypomania and defined psychotic experience as any positive response to secondary questions from the remaining domains [30].

\section{Long-term and short-term air pollution exposure attributions}

We estimated high-resolution $(20 \times 20 \mathrm{~m}$ grid points $)$ exposures at the residential address of the participants from quarterly and annual (2008-2012) nitrogen oxides $\left(\mathrm{NO}_{x}\right)$, $\mathrm{NO}_{2}$, particulate matter with a diameter of less than $10 \mu \mathrm{m}$ $\left(\mathrm{PM}_{10}\right)$ and less than $2.5 \mu \mathrm{m}\left(\mathrm{PM}_{2.5}\right)$ maps of London with the use of the KCL urban model, based on the ADMS dispersion model v4 and road source model v2.3 (Cambridge Environmental Research Consultants), measured hourly meteorological data, empirically derived $\mathrm{NO}-\mathrm{NO}_{2}-\mathrm{O}_{3}$ and PM relationships and emissions from the London Atmospheric Emissions Inventory. Sources within the KCLurban model include: road transport (exhaust and non-exhaust), large regulated industrial processes, small regulated industrial processes, large boiler plant, gas heating (domestic and industrial-commercial), oil combustion sources (domestic and commercial), coal combustion sources (domestic and 
Fig. 1 The study area within the London domain is illustrated in the top panel, with the spatial distribution of $\mathrm{PM}_{2.5}$ being illustrated in the lower panel, based on the average exposures across 2008-2012 at a resolution of $20 \times 20$ metre grid points
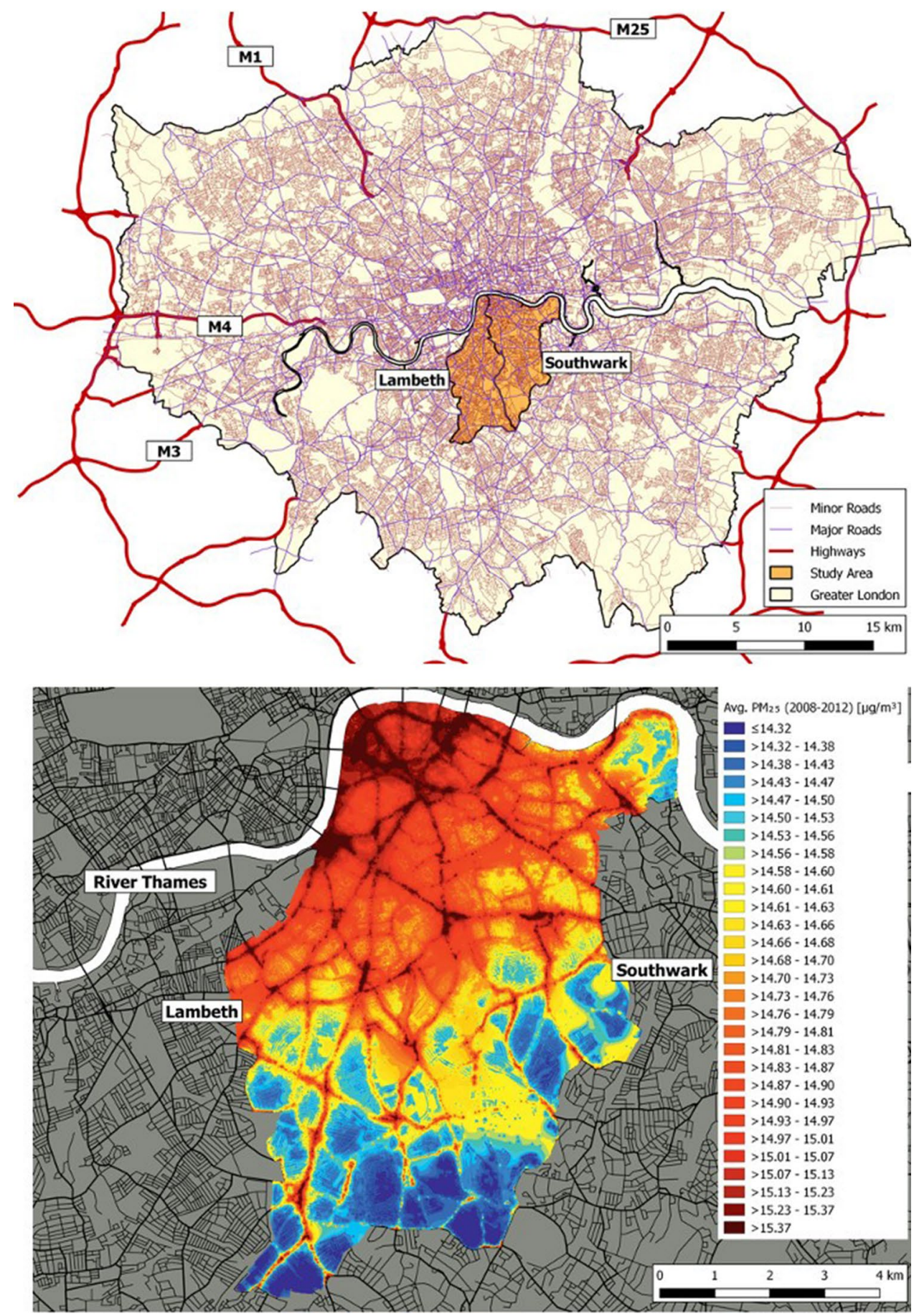

commercial), agricultural and natural sources, rail, ships, airports and others (sewage plant etc.).

Exposure data were outputted as quarterly average concentrations of nitrogen dioxide $\left(\mathrm{NO}_{2}\right)$, nitrogen oxides $\left(\mathrm{NO}_{x}\right)$, ozone $\left(\mathrm{O}_{3}\right)$, particulate matter with diameter $<10 \mu \mathrm{m}$ $\left(\mathrm{PM}_{10}\right)$ and particulate matter with an aerodynamic diameter of $<2.5 \mathrm{~mm}\left(\mathrm{PM}_{2.5}\right)$ at the residential address level for the study participants. All pollution exposure estimates were based on the quarterly average estimates at residential address level using the bilinear interpolation method using the 4 points ( $20 \mathrm{~m}$ resolution) around each address point. A comprehensive description of this model, along with information on validation against measurements and its performance against other urban dispersion models has been published previously [31]. Four-year average exposure maps for 
$\mathrm{PM}_{2.5}$ (Fig. 1) and $\mathrm{NO}_{2}$ (eFigure S1: Supplementary Online Content) are illustrated for the study area.

\section{Confounders}

The following variables were treated as confounders at the individual level: age, sex, ethnicity, smoking status, latent classes of socioeconomic status, frequency of drinking, physical activity, other chronic conditions and previous mental illness, seasonality and noise from road traffic; and at the neighbourhood level: neighbourhood levels of deprivation, perceived neighbourhood disorder. A continuous age indicator in years was recorded. Self-reported ethnicity indicated identification with one of the following groups: White British, Black Caribbean, Black African, Asian and Other ethnicity. Smoking status was based on four categories-never smoked; current smoker; ex-smoker and sporadic smoker. Latent classes of socioeconomic status (SES) were fitted as categorical indicators of professional homeowners, professional renters, skilled renters, students renters, economically inactive renters, economically inactive homeowners [32] Frequency of drinking was measured from the first item of the Alcohol Use Disorders Identification Test (AUDIT) [33] "How often do you have a drink containing alcohol?". Physical activity was derived from a yes and no answer to the question "In the last 4 weeks, outside of work, have you taken part in any sports or vigorous activities or done any exercises (e.g. jogging, bike riding)?". Participants asked to report any long-standing conditions in relation to asthma, chronic bronchitis, diabetes, high blood pressure, cancer, stroke and previous mental illness. Road-traffic noise was included as road traffic noise levels $(\mathrm{dB})$ modelled to residential postcode centroid using the Traffic Noise Exposure (TRANEX) model [34]. As the temporal variability in noise over the study period was found to be negligible, we modelled noise for one midpoint year (2010) and applied these values to other years for the same address locations across the duration of the study. We considered daytime noise, expressed as annual average A-weighted sound pressure $L_{\text {Aeq,16 h }}(07: 00-22: 59)$; nighttime noise $L_{\text {Night }}(23: 00-06: 59)$ and a day-evening-night noise $L_{\text {den }}$ (composite $L_{\text {day }}, L_{\text {eve }}$ with a $5 \mathrm{~dB}$ (A) penalty for $L_{\text {eve }}$ and $10 \mathrm{~dB}$ (A) penalty for $L_{\text {night }}$ ). As all noise metrics were highly correlated ( $\rho \geq 0.992$ ) so we therefore use $L_{\mathrm{den}}$. All noise metrics were positively skewed, and were categorised ( $L_{\mathrm{den}}:<60 \mathrm{~dB}$ (reference), 60 to $<65 \mathrm{~dB}$ and $\geq 65 \mathrm{~dB}$; $L_{\text {Aeq, } 16 \mathrm{~h}}:<55 \mathrm{~dB}$ (reference), 55 to $<60 \mathrm{~dB}, 60$ to $<65 \mathrm{~dB}$ and $\geq 65 \mathrm{~dB}$; and $L_{\text {night }}:<50 \mathrm{~dB}$ (reference), 50 to $<55 \mathrm{~dB}$, 55 to $<60 \mathrm{~dB}, 60$ to $<65 \mathrm{~dB}$ and $\geq 65 \mathrm{~dB}$ ). In order to model long-term patterns, we adjust our models for the calendar years. Perceived neighbourhood disorder was determined from four questions: "Thinking of the area you live in, how much of a problem is each of the following?" asked regarding (1) vandalism/graffiti, (2) crime, (3) safety and (4) rubbish/litter. Responses were scored on a Likert scale as 'Not a problem' (0), 'Minor' (1), 'Somewhat serious' (2) and 'Very serious' (3). Total score when all four questions were combined was not normally distributed and so a binary variable was created by splitting the highest rating given on any question into none/minor (low perceived disorder) and somewhat/very serious (high perceived disorder). The UK Official National Statistics Index of multiple deprivation (IMD) 2010 was used to define neighbourhood levels of deprivation. IMD is the government's official measure of deprivation at the small area level and scores are published for every LSOA in England [35]. The IMD 2010 is based on the data from 2008 for 38 indicators grouped into seven domains and is designed to capture multiple aspects of deprivation. Total IMD contains a health sub-domain which includes measures that aim at estimating local rates of mental disorder, so for this analysis the income and crime subdomains were used on their own as well as overall IMD rank. Although the boroughs of Lambeth and Southwark have areas of low deprivation compared to England as a whole, the majority of both boroughs are more deprived than the national average.

\section{Statistical analyses}

Data analyses were performed using STATA 14.1. Descriptive analyses were weighted for non-response within households. Air pollution exposures $\left(\mathrm{NO}_{2}, \mathrm{NO}_{x}, \mathrm{O}_{3}, \mathrm{PM}_{10}\right.$ and $\mathrm{PM}_{2.5}$ ) were analysed as continuous measures, rescaled to both interquartile (IQR) increments and increments specific to the quartile distribution of each air pollutant. Where multiple air pollutants are examined it is a common approach to rescale to the IQR, in order to calculate effect estimates for comparable increases across the different pollutants (which may have very different absolute concentration ranges). Longitudinal associations of air pollutant exposures with CMD (CIS-R), physical symptoms (PHQ-15) and self-rated general health (SF-12) were explored with the use of SELCoH 1 and SELCoH 2. In addition, we restricted our analyses for participants who remained at the same address between SELCoHs 1 and 2. Three-level random intercept logistic and ordinal regression models were used to account for the hierarchical structure of the data, considering observations from baseline (SELCoH 1) and follow up survey (SELCoH 2), individuals at level 2 and households at level 3. Since psychotic experiences were recorded only in SELCoH 1 (and not in SELCoH 2) we explored cross-sectional associations with air pollution metrics with the use of two-level random intercept logistic models considering observations from individuals at level 1 and households at level 2. Initially, all models were fitted separately for each outcome and air pollutant (Model 1-single air pollutant). This was followed by 
adjustment for age, sex, latent classes of socioeconomic status, smoking status and ethnicity (Model 2-single air pollutant); further adjusted for frequency of drinking and physical activity (Model 3-single air pollutant); further adjusted for $L_{\text {den }}$ (Model 4-joint air pollutant day-evening-time noise). As a sensitivity analysis we further adjusted separately for (1) each air pollutant with each other; (2) $L_{\mathrm{Night}}$ and $L_{\text {Aeq, } 16 \mathrm{~h}}$ (instead of $L_{\mathrm{den}}$ ); (3) seasonality (4) neighbourhood levels of deprivation (5) individual's perceived neighbourhood disorder and (6) previous chronic conditions such as longstanding illness, asthma, chronic bronchitis, diabetes, high blood pressure, cancer, stroke and previous mental illness. We further explored associations between each air pollutant and depression and anxiety scores derived as separate symptom groups from the CIS-R. Effect modification of the association between air pollutants and mental and physical health by latent classes of socioeconomic status was assessed with the inclusion of an interaction term in the above-mentioned models. We also considered annual average concentrations of $\mathrm{NO}_{2}, \mathrm{NO}_{x}, \mathrm{O}_{3}, \mathrm{PM}_{10}$ and $\mathrm{PM}_{2.5}$ in our models_-instead of quarterly average concentrations within each year and quarter of the study. Probability weights were included in all the mixed models and took account for non-response within households and attrition between SELCoHs 1 and 2. Finally, we repeated our statistical analyses using the STATA routine ice, an implementation in STATA of the multiple imputations using chained equations (MICE) and compared our results with the original analysis under the missing at random (MAR) assumption [36]. All multilevel models were run with the gllamm command [37].

\section{Results}

Longitudinal analyses were conducted in 1052 participants who participated in both surveys (SELCoH 1 and 2). Crosssectional analyses for psychotic experiences measured only in SELCoH 1 were conducted on 1655 individuals. Descriptive statistics are presented in Table 1.

\section{Is air pollution associated with CMD and psychotic experiences?}

The results from univariate longitudinal analyses presented positive associations between $\mathrm{NO}_{2}, \mathrm{NO}_{x}$ and $\mathrm{PM}_{2.5}$ with CMD (all $p$ values $<0.05$ ). The results of the univariate analyses were replicated in the multivariate analyses, when adjusted for age, sex, latent classes of SES, smoking status, ethnicity, frequency of drinking, physical activity and $L_{\text {den. }}$. Here consistent positive longitudinal associations with CMD were seen for $\mathrm{NO}_{2}$ (OR 1.39; 95\% CI 1.05, $1.85) \mathrm{NO}_{x}(\mathrm{OR} 1.37 ; 95 \% \mathrm{CI} 1.04,1.81)$ and $\mathrm{PM}_{2.5}(\mathrm{OR}$ 1.18; 95\% CI 1.02, 1.37) (Fig. 2 and Table 2). When we restricted our analyses to non-movers, stronger associations were observed for CMD. Specifically, after adjusting for all confounders, the odds ratio for CMD were 1.54 (95\% CI 1.12, 2.14) and 1.50 (95\% CI 1.10, 2.03), respectively, for $\mathrm{NO}_{2}$ and $\mathrm{NO}_{x}$ (Fig. 2 and eTable S1: Supplementary Online Content). For non-movers, we also observed negative associations between $\mathrm{O}_{3}$ and CMD (Fig. 2 and eTable S1: Supplementary Online Content). In addition, our per quartile analysis presented an almost twofold increase in CMD for participants with exposure in the 4 th quartile $\left(>24 \mu \mathrm{g} / \mathrm{m}^{3}\right.$ ) compared to participants with exposure to the 1 st quartile $\left(12.4 \mu \mathrm{g} / \mathrm{m}^{3}\right)$ for $\mathrm{PM}_{2.5}$ for the overall sample of SELCoH 1 and $2(n=1052$; OR $1.93 ; 95 \%$ CI $1.22,3.05)$ and non-movers $(n=754$; OR 1.77; 95\% CI 1.03, 3.25) (eTable S2 and eTable S3: Supplementary Online Content). $\mathrm{PM}_{10}$ and Psychotic experiences extracted from SELCoH 1 showed strong evidence for a cross-sectional association with each air pollutant (OR 1.33; 95\% CI 1.14, 1.55; Model 4; Fig. 3).

\section{Is air pollution associated with poor psychical symptoms and self-rated general health?}

The results from univariate and multivariate longitudinal analyses showed positive associations for $\mathrm{NO}_{2}, \mathrm{NO}_{x}$ and $\mathrm{PM}_{2.5}$ with an increased total score for PHQ-15 (all $p$ values <0.05) (Fig. 2 and eTable S2: Supplementary Online Content). Similar odds ratios were observed when we restricted our analyses to non-movers (eTable S1-Supplementary Online Content). For SF-12, none of the air pollutants showed association (Fig. 2 and Table 2), yet, for non-movers only, SF-12 showed a positive association with $\mathrm{NO}_{2}$ and $\mathrm{NO}_{x}$ (all $p$ values $\left.<0.05\right)$ and negative associations with $\mathrm{O}_{3}$ (eTable $\mathrm{S} 2$ and eTable $\mathrm{S} 3$ : Supplementary Online Content).

\section{Sensitivity analyses}

All odds ratio estimates were attenuated when two-air pollutant models were employed-this is due to issues of high multicollinearity (all Pearson correlation coefficients $>0.75$ between the air pollutants and the variance inflation factor, an indicator of multicollinearity, which was $>10$ for all models; eTable S4). Modifying our model to account for the road-traffic noise separately for $L_{\mathrm{Night}}$ and $L_{\text {Aeq, } 16 \mathrm{hr}}$ (eTable $\mathrm{S} 4$ ) or employing annual average concentrations of air pollutants (instead of quarterly) (eTable S5) made no significant difference in the estimates of odds ratio and $95 \%$ confidence intervals of models. Further adjusting separately for other chronic conditions, seasonality, neighbourhood levels of deprivation and perceived 
Table 1 Characteristics of the study population and distribution of mental health outcomes, exposures and confounders within the two waves of the South East London Community Survey (SELCoH 1 and 2)

\begin{tabular}{|c|c|c|c|c|}
\hline \multirow[t]{2}{*}{ Survey } & \multicolumn{2}{|l|}{ SELCoH 1} & \multicolumn{2}{|l|}{ SELCoH 2} \\
\hline & Number (\%) unless otherwise stated & $n$ & Number $(\%)$ unless otherwise stated & $n$ \\
\hline Age & Mean: 40; SD: 16.9 & 1698 & Mean: 43; SD: 16.5 & 1052 \\
\hline \multicolumn{5}{|l|}{ Gender } \\
\hline Male & $737(47.6)$ & \multirow[t]{2}{*}{1698} & $437(47.5)$ & \multirow[t]{2}{*}{1052} \\
\hline Female & $961(52.4)$ & & $615(52.5)$ & \\
\hline \multicolumn{5}{|l|}{ Latent classes of socioeconomic status } \\
\hline Professional, homeowners & $470(27.8)$ & \multirow[t]{6}{*}{1698} & $351(32.6)$ & \multirow[t]{6}{*}{1052} \\
\hline Professional, renters & $112(6.9)$ & & $43(4.7)$ & \\
\hline Skilled, renters & $351(20.7)$ & & $244(22.6)$ & \\
\hline Students, renters & $230(14.5)$ & & $103(12.4)$ & \\
\hline Economically inactive, renters & $407(23.0)$ & & $213(19.4)$ & \\
\hline Economically inactive, homeowners & $128(7.1)$ & & $98(8.1)$ & \\
\hline \multicolumn{5}{|l|}{ Smoking status } \\
\hline Never smoked & $514(30.4)$ & \multirow[t]{4}{*}{1685} & $426(40.4)$ & \multirow[t]{4}{*}{1052} \\
\hline Current smoker & $423(25.6)$ & & $225(22.6)$ & \\
\hline Ex-smoker & $450(26.0)$ & & $350(31.4)$ & \\
\hline Sporadic smoker & $298(18.0)$ & & $51(5.2)$ & \\
\hline \multicolumn{5}{|l|}{ Frequency of alcoholic drink } \\
\hline Never & $379(22.0)$ & \multirow[t]{5}{*}{1689} & $212(18.9)$ & \multirow[t]{5}{*}{1052} \\
\hline Monthly or less & $377(22.2)$ & & $228(21.8)$ & \\
\hline Two or four times a month & $290(17.4)$ & & $183(18.4))$ & \\
\hline Two or three times a week & $380(22.8)$ & & $256(24.9)$ & \\
\hline Four or more times a week & $263(15.6)$ & & $173(15.8)$ & \\
\hline \multicolumn{5}{|l|}{ Physically active } \\
\hline No & $722(42.0)$ & \multirow[t]{2}{*}{1670} & $408(41.3$ & \multirow[t]{2}{*}{1052} \\
\hline Yes & $948(58.0)$ & & $644(58.6)$ & \\
\hline \multicolumn{5}{|l|}{ Ethnicity } \\
\hline White & $1051(61.6)$ & \multirow[t]{5}{*}{1698} & $688(63.8)$ & \multirow[t]{4}{*}{1052} \\
\hline Black Caribbean & $143(8.4)$ & & $79(7.8)$ & \\
\hline Black African & $234(14.0)$ & & $131(13.0)$ & \\
\hline Asian & $63(3.7)$ & & $40(3.8)$ & \\
\hline Other & $205(12.3)$ & & $114(11.4)$ & 1 \\
\hline \multicolumn{5}{|l|}{ Perceived neighbourhood disorder } \\
\hline None/minor & $1042(62.5 \%)$ & 1666 & $1042(61.6 \%)$ & 1051 \\
\hline Somewhat/very serious & $626(37.6 \%)$ & & $403(38.3 \%)$ & \\
\hline Index of multiple deprivation & Mean: 30.4; SD: 8.4 & 1666 & Mean: 29.7; SD: 8.5 & 1051 \\
\hline Air pollutant median concentrations $(\mu$ & & & & \\
\hline $\mathrm{NO}_{2}$ & Median: 39.6 (IQR: 17.3) & & Median: 35.8 (IQR: 19.6) & \\
\hline $\mathrm{NO}_{x}$ & Median: 67.4 (IQR: 45.6) & & Median: 57.0 (IQR: 48.0) & \\
\hline $\mathrm{O}_{3}$ & Median: 31.7 (IQR: 21.3) & & Median: 35.7 (IQR: 14.9) & \\
\hline $\mathrm{PM}_{10}$ & Median: 22.6 (IQR: 3.6) & 1698 & Median: 18.5 (IQR: 4.6) & 937 \\
\hline $\mathrm{PM}_{2.5}$ & Median: 14.2 (IQR: 3.2) & & Median: 13.7 (IQR: 2.6) & \\
\hline 24-h noise metric $\left(L_{\mathrm{den}}\right)(\mathrm{dB})$ & & & & \\
\hline$<60$ & $1196(70.4)$ & 1698 & $729(69.4)$ & 1052 \\
\hline$[60,65)$ & $160(9.5)$ & & $96(9.1)$ & \\
\hline$\geq 65$ & $342(20.1)$ & & $227(21.5)$ & \\
\hline Daytime noise metric $\left(L_{\text {Aeq, } 16 \mathrm{~h}}\right)(\mathrm{dB})$ & & & & \\
\hline$<55$ & $329(19.3)$ & 1698 & $196(18.1)$ & 1052 \\
\hline
\end{tabular}


Table 1 (continued)

\begin{tabular}{|c|c|c|c|c|}
\hline \multirow[t]{2}{*}{ Survey } & \multicolumn{2}{|l|}{ SELCoH 1} & \multicolumn{2}{|l|}{ SELCoH 2} \\
\hline & Number $(\%)$ unless otherwise stated & $n$ & Number $(\%)$ unless otherwise stated & $n$ \\
\hline$[55,60)$ & $983(58.0)$ & & $598(56.5)$ & \\
\hline$[60,65)$ & $155(9.1)$ & & $103(9.8)$ & \\
\hline$\geq 65$ & $231(13.6)$ & & $155(14.6)$ & \\
\hline \multicolumn{5}{|c|}{ Night-time noise metric $\left(L_{\text {night }}\right)(\mathrm{dB})$} \\
\hline$<50$ & $808(47.7)$ & 1698 & $493(46.9)$ & 1052 \\
\hline$[50,55)$ & $494(29.2)$ & & $143(28.2)$ & \\
\hline$[55,60)$ & $143(8.3)$ & & $93(8.8)$ & \\
\hline$[60,65)$ & $171(9.9)$ & & $112(10.1)$ & \\
\hline$\geq 65$ & $82(4.9)$ & & $58(6.0)$ & \\
\hline \multicolumn{5}{|c|}{ Revised Clinical Interview Schedule (CIS-R) } \\
\hline$<12$ & $1296(77.0)$ & 1692 & $821(77.9)$ & 1052 \\
\hline $12+$ & $396(22.9)$ & & $231(22.1)$ & \\
\hline \multicolumn{5}{|c|}{ Patient Health Questionnaire (PHQ-15) } \\
\hline Minimal (0-4) & $936(60.6)$ & 1567 & $553(55.9)$ & 1000 \\
\hline Low $(5-9)$ & 439 (27.6) & & $290(28.7)$ & \\
\hline Medium (10-14) & $153(9.4)$ & & $121(11.8)$ & \\
\hline High (15-30) & $39(2.3)$ & & $36(3.5)$ & \\
\hline \multicolumn{5}{|c|}{ 12-Item Short Form Health Survey (SF-12) } \\
\hline Excellent/very good & $821(48.9)$ & 1688 & $548(53.4)$ & 1052 \\
\hline Good & $571(34.1)$ & & $308(29.3)$ & \\
\hline Fair/poor & $296(17.0)$ & & $196(17.3)$ & \\
\hline \multicolumn{5}{|l|}{ Psychotic experiences } \\
\hline No & $1382(81.3)$ & 1686 & NA & NA \\
\hline Yes & $304(18.7)$ & & NA & NA \\
\hline Long-standing illness & $654(39.2)$ & 1666 & $487(46.3)$ & 1051 \\
\hline Asthma & $132(7.9)$ & 1666 & $100(9.5)$ & 1051 \\
\hline Chronic bronchitis & $8(0.4)$ & 1666 & $6(0.5)$ & 1051 \\
\hline Diabetes & $73(4.3)$ & 1666 & $57(5.4)$ & 1051 \\
\hline High blood pressure & $150(9.0)$ & 1666 & $142(13.5)$ & 1051 \\
\hline Cancer & $23(1.3)$ & 1666 & $17(1.62)$ & 1051 \\
\hline Stroke & $13(0.7)$ & 1666 & $16(1.5)$ & 1051 \\
\hline Previous mental illness & $100(6.0)$ & 1666 & $81(7.7)$ & 1051 \\
\hline
\end{tabular}

Weighted percentages are presented to account for survey design; frequencies are unweighted and may not add up due to missing values

neighbourhood disorder also made no significant difference to our results (eTable S6 and eTable 7: Supplementary Online Content). When we derived depression and anxiety scores as separate symptom groups from the CIS-R no evidence of an association were observed with each air pollutant, although direction of odds ratio was on the expected direction (eTable 8-Supplementary Online Content). No evidence of an effect modification of the association was found between each outcome and air pollutant by individuals' SES (all $p$ values $>0.05$; eTable S9). In addition, odds ratio estimates did not change substantially when we replicate our analyses with the use of the MICE procedure (eTable S10).

\section{Discussion}

In this study, we addressed the association between air pollution, CMD and psychotic experiences in adults within a high traffic inner city area. We demonstrated consistent longitudinal associations of long-term exposure to air pollutants $\left(\mathrm{NO}_{2}, \mathrm{NO}_{x}\right.$ and $\left.\mathrm{PM}_{2.5}\right)$ with mental disorders and physical symptoms indicative of mental distress based on the standardised and validated interviews and questionnaires, after adjusting for a large number of confounders, including individual level socioeconomic status and urban noise. These associations were more pronounced for $\mathrm{NO}_{2}$ and $\mathrm{NO}_{x}$ in the subset of non-movers across the two-survey dates. Our data also support a cross-sectional association between 


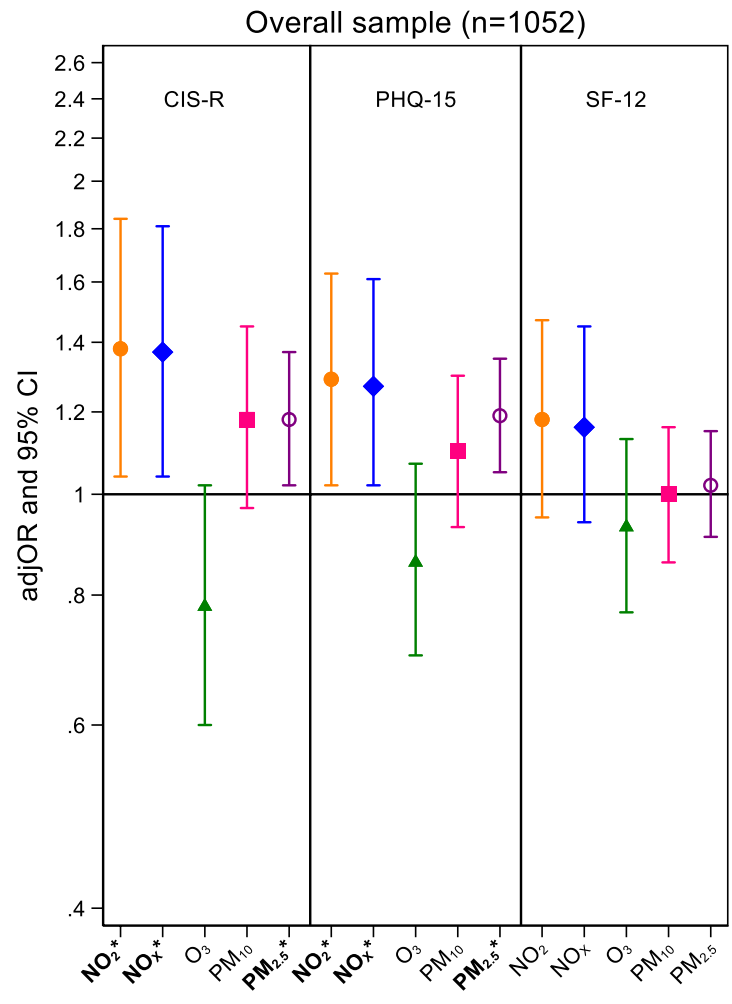

Fig. 2 Adjusted odds ratios (adjOR) and their corresponding 95\% intervals (CI) represent increase in risk for common mental disorders (CIS-R), physical symptoms (PHQ-15) and self-rated general health $(\mathrm{SF}-12)$ per IQR increase in air pollutant $\left(\mathrm{NO}_{2}, \mathrm{NO}_{x}, \mathrm{O}_{3}, \mathrm{PM}_{10}\right.$,

$\mathrm{PM}_{10}$ exposure and psychotic experiences. There was no evidence to suggest modification of the observed associations by socioeconomic characteristics.

\section{Strengths and limitations of this study}

The present study investigated a large, representative group of individuals within an inner-city population, reflecting the London's ethnic diversity and broad spectrum of socioeconomic conditions. The study area consistent of 2 densely populated London boroughs of Lambeth and Southwark (combined population of 638,200), which experience similar levels of annual air pollution compared to London (e.g. median levels of $\mathrm{PM}_{2.5}$ are $14.2 \mu \mathrm{g} / \mathrm{m}^{3}$ vs. London $14.4 \mu \mathrm{g} /$ $\mathrm{m}^{3}$ levels [38]). For air pollution exposures, our study had higher spatial $[9,12]$ and temporal precision than previous work [10,39], thereby reducing potential exposure misclassification, especially for primary traffic-related air pollutants such as $\mathrm{NO}_{2}$. However, some exposure misclassification remains as the participants of the SELCoH study may have had different exposure patterns due to their everyday mobility patterns or being away from their residence (e.g. workplace or transport) for a large percentage of their day or indoor air pollution exposures or exposure modification

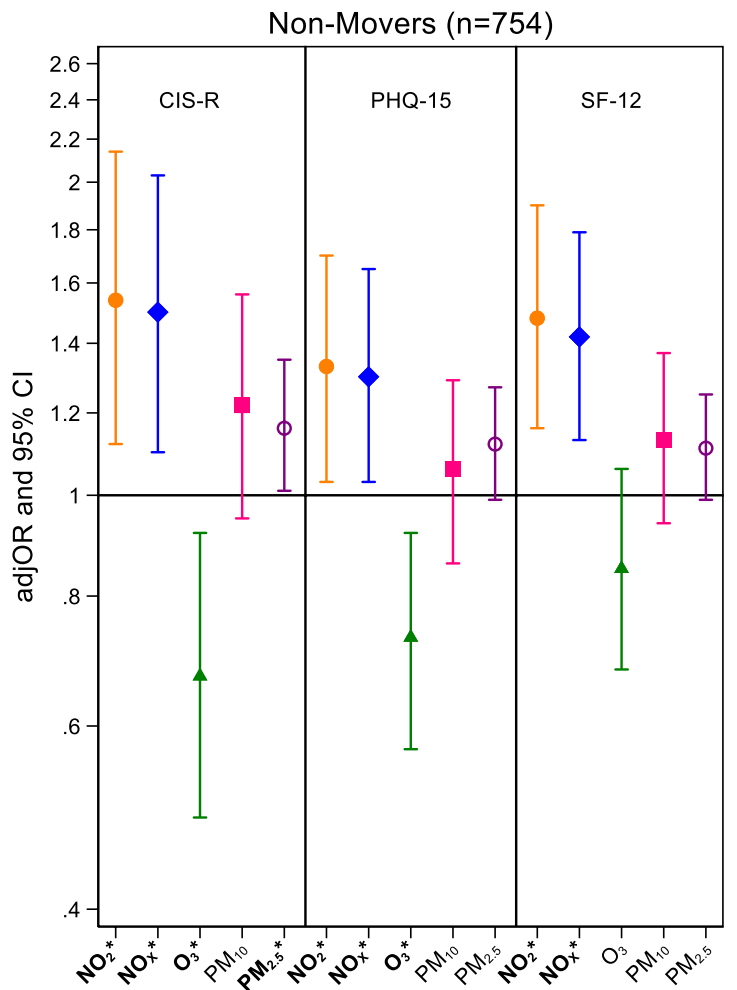

$\mathrm{PM}_{2.5}$ ) levels $\left(\mu \mathrm{g} / \mathrm{m}^{3}\right)$. All models are adjusted for age, sex, latent classes of SES, smoking status, ethnicity, frequency of drinking, physical activity and $L_{\mathrm{den}}$

owing to behaviours (e.g. opening windows) or building characteristics (e.g. bedroom façade). The significance of this exposure misclassification was potentially greatest for pollutants that varying in concentrations markedly with distance from source, such a $\mathrm{NO}_{2}$ or where there was marked diurnal and seasonal variations, e.g. $\mathrm{O}_{3}$. A novel aspect of our analysis was the ability to study the modelled effects of air pollution on each outcome after adjusting for roadtraffic noise, overcoming acknowledged limitations from other studies [7, 12]. We therefore believe that the associations observed are robust and were persistent in multiple sensitivity analyses. In addition, the fact that our study revealed these outcomes with a relatively narrow range of exposures, with the majority of subjects living in high traffic areas, implies that a more pronounced effect may exist between urban and rural populations.

One limitation of the study is that we were unable to consider the association between mental and physical health with shorter term, e.g. daily fluctuations in air pollution. Furthermore, a previous study had shown only moderate correlations between the air pollution and noise models used in this study, thus indicating that noise is not a potential candidate to explain the association between traffic-related air pollution [40]. We used a detailed noise model which 
Table 2 Longitudinal associations between air pollutants $\left(\mathrm{NO}_{2}, \mathrm{NO}_{x}\right.$, $\mathrm{O}_{3}, \mathrm{PM}_{10}, \mathrm{PM}_{2.5}$ ) and common mental disorders (CIS-R), physical symptoms (PHQ-15) and self-rated general health (SF-12) with the use of the SELCoH 1 and 2 surveys

\begin{tabular}{|c|c|c|c|c|}
\hline & $\begin{array}{l}\text { Model } 1^{ \pm} \\
\text {OR } 95 \% \text { CI }\end{array}$ & $\begin{array}{l}\text { Model } 2^{ \pm \pm} \\
\text {OR } 95 \% \text { CI }\end{array}$ & $\begin{array}{l}\text { Model } 3^{ \pm \pm \pm} \\
\text {OR 95\% CI }\end{array}$ & $\begin{array}{l}\text { Model } 4^{ \pm \pm \pm \pm} \\
\text {OR } 95 \% \text { CI }\end{array}$ \\
\hline \multicolumn{5}{|l|}{$\mathrm{NO}_{2}$} \\
\hline CIS-R & $\begin{array}{l}1.44 * \\
1.07,1.92\end{array}$ & $\begin{array}{l}1.36^{*} \\
1.02,1.82\end{array}$ & $\begin{array}{l}1.39 * \\
1.05,1.85\end{array}$ & $\begin{array}{l}1.39 * \\
1.05,1.85\end{array}$ \\
\hline PHQ-15 & $\begin{array}{l}1.33^{*} \\
1.04,1.71\end{array}$ & $\begin{array}{l}1.28^{*} \\
1.01,1.62\end{array}$ & $\begin{array}{l}1.30 * \\
1.03,1.65\end{array}$ & $\begin{array}{l}1.30 * \\
1.02,1.64\end{array}$ \\
\hline SF-12 & $\begin{array}{l}1.20 \\
0.95,1.52\end{array}$ & $\begin{array}{l}1.15 \\
0.93,1.44\end{array}$ & $\begin{array}{l}1.18 \\
0.95,1.47\end{array}$ & $\begin{array}{l}1.17 \\
0.94,1.46\end{array}$ \\
\hline \multicolumn{5}{|l|}{$\mathrm{NO}_{x}$} \\
\hline CIS-R & $\begin{array}{l}1.41^{*} \\
1.06,1.88\end{array}$ & $\begin{array}{l}1.35^{*} \\
1.02,1.79\end{array}$ & $\begin{array}{l}1.38 * \\
1.04,1.82\end{array}$ & $\begin{array}{l}1.37 * \\
1.04,1.81\end{array}$ \\
\hline PHQ-15 & $\begin{array}{l}1.31 * \\
1.03,1.66\end{array}$ & $\begin{array}{l}1.26^{*} \\
1.01,1.58\end{array}$ & $\begin{array}{l}1.29 * \\
1.02,1.62\end{array}$ & $\begin{array}{l}1.28 * \\
1.02,1.61\end{array}$ \\
\hline SF-12 & $\begin{array}{l}1.17 \\
0.93,1.47\end{array}$ & $\begin{array}{l}1.13 \\
0.91,1.40\end{array}$ & $\begin{array}{l}1.16 \\
0.94,1.43\end{array}$ & $\begin{array}{l}1.15 \\
0.93,1.42\end{array}$ \\
\hline \multicolumn{5}{|l|}{$\mathrm{O}_{3}$} \\
\hline CIS-R & $\begin{array}{l}0.77 \\
0.59,1.01\end{array}$ & $\begin{array}{l}0.80 \\
0.61,1.10\end{array}$ & $\begin{array}{l}0.78 \\
0.60,1.02\end{array}$ & $\begin{array}{l}0.78 \\
0.60,1.02\end{array}$ \\
\hline PHQ-15 & $\begin{array}{l}0.86 \\
0.69,1.07\end{array}$ & $\begin{array}{l}0.89 \\
0.72,1.10\end{array}$ & $\begin{array}{l}0.86 \\
0.70,1.07\end{array}$ & $\begin{array}{l}0.86 \\
0.70,1.07\end{array}$ \\
\hline SF-12 & $\begin{array}{l}0.96 \\
0.78,1.18\end{array}$ & $\begin{array}{l}0.97 \\
0.80,1.18\end{array}$ & $\begin{array}{l}0.93 \\
0.77,1.13\end{array}$ & $\begin{array}{l}0.93 \\
0.77,1.13\end{array}$ \\
\hline \multicolumn{5}{|l|}{$\mathrm{PM}_{10}$} \\
\hline CIS-R & $\begin{array}{l}1.25^{*} \\
1.01,1.54\end{array}$ & $\begin{array}{l}1.19 \\
0.97,1.46\end{array}$ & $\begin{array}{l}1.19 \\
0.97,1.45\end{array}$ & $\begin{array}{l}1.19 \\
0.97,1.45\end{array}$ \\
\hline PHQ-15 & $\begin{array}{l}1.13 \\
0.94,1.35\end{array}$ & $\begin{array}{l}1.11 \\
0.93,1.31\end{array}$ & $\begin{array}{l}1.11 \\
0.93,1.31\end{array}$ & $\begin{array}{l}1.10 \\
0.93,1.30\end{array}$ \\
\hline SF-12 & $\begin{array}{l}1.03 \\
0.88,1.21\end{array}$ & $\begin{array}{l}1.00 \\
0.86,1.16\end{array}$ & $\begin{array}{l}1.00 \\
0.86,1.16\end{array}$ & $\begin{array}{l}1.00 \\
0.86,1.16\end{array}$ \\
\hline \multicolumn{5}{|l|}{$\mathrm{PM}_{2.5}$} \\
\hline CIS-R & $\begin{array}{l}1.20^{*} \\
1.03,1.41\end{array}$ & $\begin{array}{l}1.18^{*} \\
1.01,1.37\end{array}$ & $\begin{array}{l}1.18^{*} \\
1.02,1.38\end{array}$ & $\begin{array}{l}1.18^{*} \\
1.02,1.37\end{array}$ \\
\hline PHQ-15 & $\begin{array}{l}1.22 * * \\
1.07,1.39\end{array}$ & $\begin{array}{l}1.20 * * \\
1.06,1.36\end{array}$ & $\begin{array}{l}1.19 * * \\
1.05,1.35\end{array}$ & $\begin{array}{l}1.19 * * \\
1.04,1.35\end{array}$ \\
\hline SF-12 & $\begin{array}{l}1.07 \\
0.94,1.22\end{array}$ & $\begin{array}{l}1.03 \\
0.92,1.16\end{array}$ & $\begin{array}{l}1.02 \\
0.91,1.15\end{array}$ & $\begin{array}{l}1.02 \\
0.91,1.15\end{array}$ \\
\hline
\end{tabular}

Odds ratios (OR) and their corresponding 95\% intervals (CI) represent increase in risk for mental disorders and physical symptoms per IQR increase in air pollutant levels $\left(\mu \mathrm{g} / \mathrm{m}^{3}\right)$

${ }^{*} p<0.05,{ }^{* *} p<0.01{ }^{ \pm}$Model 1: unadjusted ${ }^{ \pm \pm}$Model 2: Adjusted for age, sex, latent classes of SES, smoking status, ethnicity ${ }^{ \pm \pm \pm}$Model 3: Adjusted for age, sex, latent classes of SES, smoking status, ethnicity, frequency of drinking, physical activity ${ }^{ \pm \pm \pm \pm}$Model 4: Adjusted for age, sex, latent classes of SES, smoking status, ethnicity, frequency of drinking, physical activity and $L_{\mathrm{den}}$

follows the UK Calculation of Road Traffic Noise method [34]. The model takes into account noise barriers, including buildings and land cover which accounts to some degree for vegetation. Our noise model is likely to have overestimated and underestimated noise on some minor roads owing to the use of a constant for traffic on minor roads where detailed traffic data were not available. However, in order to reduce potential exposure misclassification, we categorised noise exposure for our analysis, when we further adjusted our models for road traffic noise Consistent with this view, we observed little change in effect size after adjusting for road-traffic noise. The $51.9 \%$ household participation rate and the $38.1 \%$ attrition rate were low and we were unable to characterise non-respondents' demographic variables to rule out possible bias owing to non-participation. Nevertheless, samples were representative of the local population on most sociodemographic characteristics [25] and probability weights were estimated to address both household participation and sample attrition in our statistical models. Furthermore, multiple imputations were employed as additional sensitive analysis to handle attrition in our models. A further weakness of this study, which is shared with the majority of studies on this topic, is the lack of air pollution data capturing an accurate picture of lifetime or cumulative exposure Because of central nervous system plasticity during development, children are particularly susceptible to harmful effects of air pollution on neurodevelopment and therefore to longterm cognitive health. Therefore, one would wish to capture early life exposures to provide comprehensive understanding of how changes in individual cognitive trajectories might influence transition to lower IQ, attention deficit hyperactivity disorder (ADHD) and autism spectrum disorder during childhood and psychiatric symptoms in adulthood [41]. Unfortunately, these links have been largely unexplored in the current literature. In our study, the quantification of the impact of air pollution on mental and psychical health has been undertaken through a single pollutant approach, due to the measurement and source complexities and regulatory strategies of air quality management, which have addressed a single pollutant at a time. However, from a modelling perspective effect estimates could be augmented with a multipollutant approach $[42,43]$ as currently they might provide an underestimation of the effect sizes.

\section{Comparison to other studies}

Our single air pollutant model findings are partly consistent with recent studies in adults, which report increased risk of mental disorders with $\mathrm{NO}_{2}$ and $\mathrm{PM}_{25}$. The majority of previous studies have focused on depression and anxiety and presented positive associations with increased concentrations of $\mathrm{NO}_{2}$ [39] and $\mathrm{PM}_{2.5}[13,14]$. Our study is the first to assess the relationship between long-term exposure to air pollution $\left(\mathrm{PM}_{10}\right)$ and psychotic experiences in the UK in adults. A recent UK study has reported similar effect size of long-term exposure to $\mathrm{PM}_{10}$ and elevated risk in psychotic experiences in adolescents (OR 1.27; 95\% CI 0.98-1.65) [10]. In Sweden, children and adolescents residing in areas with high 
Fig. 3 Adjusted odds ratios (adjOR) and their corresponding $95 \%$ intervals (CI) represent increase in risk for psychotic experiences per IQR increase in air pollutant $\left(\mathrm{NO}_{2}, \mathrm{NO}_{x}, \mathrm{O}_{3}\right.$, $\left.\mathrm{PM}_{10}, \mathrm{PM}_{2.5}\right)$ levels $\left(\mu \mathrm{g} / \mathrm{m}^{3}\right)$. Model 1: unadjusted; Model 2: Adjusted for age, sex, latent classes for SES, smoking status, ethnicity; Model 3: Adjusted for age, sex, latent classes for SES, smoking status, ethnicity, frequency of drinking, physical activity ${ }^{ \pm \pm \pm \pm}$Model 4: for age, sex, latent classes for SES, smoking status, ethnicity, frequency of drinking, physical activity and $L_{\text {den }}$

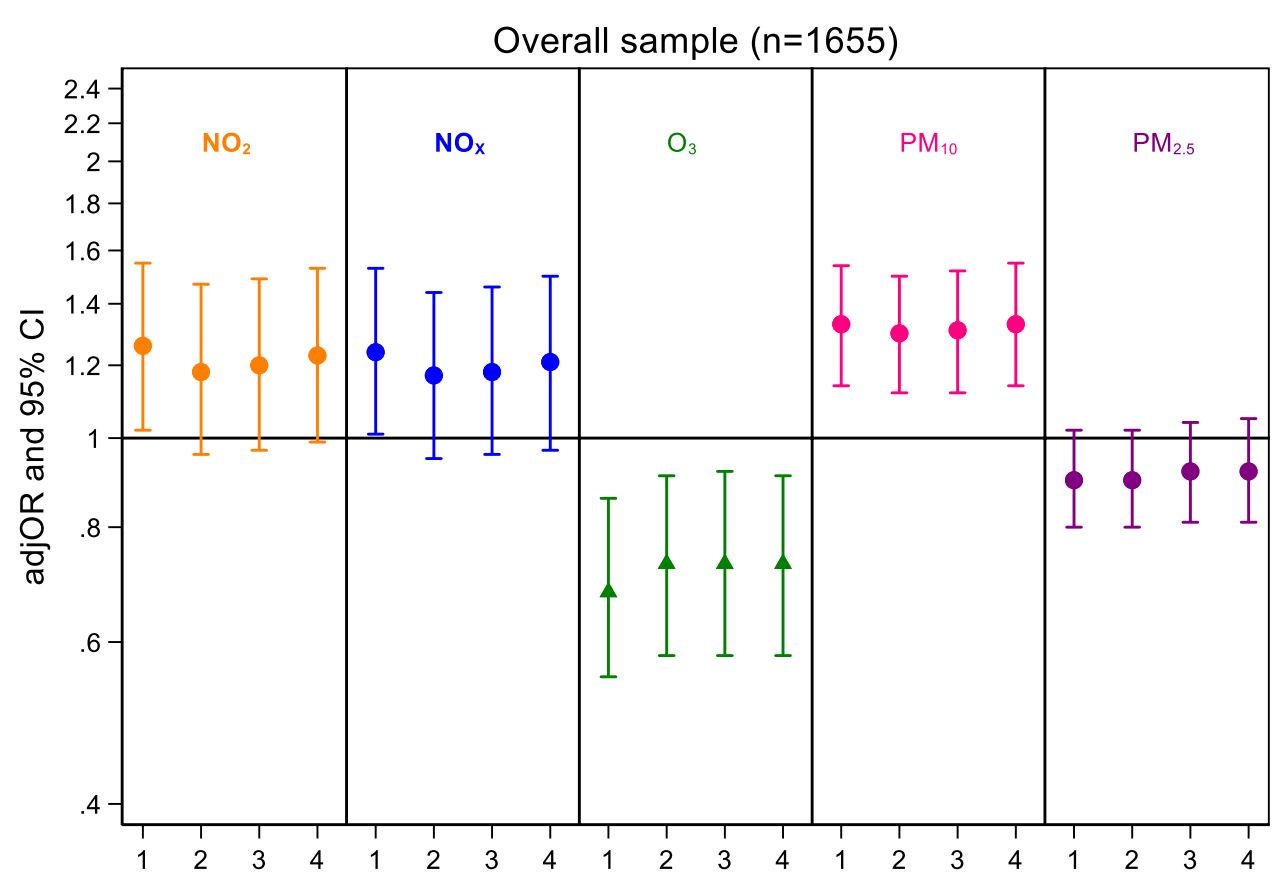

$\mathrm{PM}_{10}$ concentrations were more likely to have a dispensed medication for a psychiatric disorder than those residing in areas with low $\mathrm{PM}_{10}$ concentrations [7]. In adults, a summary measure of air quality constructed from a wide range of environmental compounds was associated with increased risk of schizophrenia in the US and Denmark [9]. When a re-analysis of the same cohort was conducted with highresolution air pollution estimates, inconclusive evidence was observed between $\mathrm{PM}_{10}$ and schizophrenia [44]. Short-term acute effects of $\mathrm{PM}_{10}$ were also associated with increased risk of psychosis morbidity [45] and hospital admissions for schizophrenia [46] in two studies conducted in China. $\mathrm{NO}_{2}$ and $\mathrm{NO}_{x}$ as the sum of $\mathrm{NO}_{2}$ and nitric oxide (NO), are associated with motor vehicle exhausts and are common markers of traffic-related pollution, specifically in cities while $\mathrm{PM}_{10}$ and $\mathrm{PM}_{2.5}$ are commonly used as a proxy of ambient air pollution [47]. Our results for a negative association of ozone $\left(\mathrm{O}_{3}\right)$ with CMD are contradictory to similar studies published previously on the topic [23]. This is due to the fact that $\mathrm{O}_{3}$ has an opposite spatial distribution than e.g. $\mathrm{NO}_{2}$ and we would therefore expect a negative association given the positive association seen with $\mathrm{NO}_{2}$, indicating that trafficrelated air pollutants are driving the observed patterns.

\section{Potential mechanisms}

A broad range of psychiatric conditions have been associated with systemic and CNS inflammation and oxidative stress $[15,48,49]$ and neurogenerative pathophysiologic processes $[50,51]$ following air pollution exposures. Animal studies have further demonstrated that inflammation and oxidative stress may also affect the CNS [15, 52, 53]. In an early seminal study, exploring whether air pollution may be a risk factor of neurogenerative disease, healthy feral dogs chronically exposed to traffic-related pollution showed enhance oxidative, immunological and genetic damage in olfactory bulbs, frontal, cortex and hippocampus [54]. Recent evidence has also demonstrated elevated numbers of combustion derived magnetite nanoparticles in the brains of urban dwellers [17], associated with pathological alterations in neurons, glia and neurovascular units [18] with evidence of enhanced particle numbers in archived brains of dementia [55]. Neuroinflammation and neurotoxicity appears to be important both for depression [56] and psychosis [57] for both short- and longterm effects of air pollution. Furthermore, uncertainties still exist on how inhaled nanoparticles (particulate and ultrafine particles) gain access to the brain and alter brain structure [19, 20, 55, 58]. Particulate matter may enter brain via (1) the lungs, which could induce respiratory tract inflammation and could result in activation of microglia and oxidative, immunological and genetic damage; (2) the bloodstream, crossing the blood-brain barrier; (3) the nasal pathway and the olfactory nerve where nanoparticles travel directly to the brain, producing direct toxic damage to the limbic system and brain degeneration due to oxidative stress [55, 59].

\section{Conclusions}

Our results are consistent with urban air pollution having a significant impact on poor mental health, which cannot be explained by other indices of urbanicity or socioeconomic 
deprivation, although an underlying mechanistic understanding of causation is still required to substantiate this linkage. We estimate a twofold increase in terms of common mental disorder cases directly attributable to residential annual exposures to $\mathrm{PM}_{2.5}>15.5 \mu \mathrm{g} / \mathrm{m}^{3}$, below the EU value air quality target value of $25 \mu \mathrm{g} / \mathrm{m}^{3}$. The public health impact of air pollution on physical health is increasingly well understood and studies have shown that improved air quality is associated with a range quantifiable health benefits [52]. In 2016, the World Health Organization (WHO) reported that $91 \%$ of the world's population lives in places where air quality exceeds WHO guideline limits with 4.2 millions of premature deaths being a result of ambient air pollution with $91 \%$ of these premature deaths occurring in low- and middle-income countries. Recent evidence also indicated the need for revision of WHO air quality guidelines in even lower limits to protect human health [60]. There should be special attention for innovative measures to improve air quality, such as the Ultra-Low emission Zone in London (ULEZ), the introduction of buses and cars powered by electricity and boldly rethink the way that we plan our car-less visions of cities-an urgency which will be more apparent during the aftermath of the COVID-19 pandemic era [61]. Improving air quality is a tractable, though complex issue [31] and therefore measures to reduce air pollution overall within cities or to reduce individuals' exposures through behaviour change may represent a potentially impactful primary health measure to mitigate against mental disorders within the urban population.

Acknowledgements This work was supported by the Economic and Social Research Council [RES-177-25-0015]. This paper represents independent research part-funded by the National Institute for Health Research (NIHR) Biomedical Research Centre at South London and Maudsley NHS Foundation Trust and King's College London. The views expressed are those of the author(s) and not necessarily those of the NHS, the NIHR or the Department of Health and Social Care. Ioannis Bakolis is supported by the NIHR Biomedical Research Centre at South London and Maudsley NHS Foundation Trust and by the NIHR Collaboration for Leadership in Applied Health Research and Care South London at King's College Hospital NHS Foundation Trust, King's College London. Dr. Mudway's involvement in this study was part funded by the National Institute for Health Research (NIHR) Health Protection Research Unit in Environmental Exposures and Health, a partnership between Public Health England and Imperial College London. The views expressed are those of the author(s) and not necessarily those of the NIHR, Public Health England or the Department of Health and Social Care. This work was further supported by the UK Medical Research Council via the MRC Centre for Environment and Health.

Author contributions IB, ISM, SLH, RS, NS and MH conceived the study and elaborated the design. MH, SLH, IB, ISM, SB, DF, JG and DD gathered data. MP, MB and SM linked the data. ISM, DD and SB developed the air quality models. DF and JG developed the noise models. IB and RH did the statistical analysis. IB and ISM wrote the first draft, on which all authors commented. All authors have given their approval for the publication of this manuscript and agree to be accountable for all aspects of the work to ensure that the questions related to the accuracy or integrity of any part of the work are appropriately investigated and resolved.

Funding Funders supported the data collection stage by providing salaries for the researchers collecting the data and had no role in study design, data analysis, data interpretation or writing of the report. The corresponding author had full access to all data in the study and final responsibility for the decision to submit the report for publication.

\section{Compliance with ethical standards}

Conflict of interest We declare no competing interests.

Open Access This article is licensed under a Creative Commons Attribution 4.0 International License, which permits use, sharing, adaptation, distribution and reproduction in any medium or format, as long as you give appropriate credit to the original author(s) and the source, provide a link to the Creative Commons licence, and indicate if changes were made. The images or other third party material in this article are included in the article's Creative Commons licence, unless indicated otherwise in a credit line to the material. If material is not included in the article's Creative Commons licence and your intended use is not permitted by statutory regulation or exceeds the permitted use, you will need to obtain permission directly from the copyright holder. To view a copy of this licence, visit http://creativecommons.org/licenses/by/4.0/.

\section{References}

1. OECD (2014) The cost of air pollution: health impacts of road transport. OECD Publishing, Paris. https://doi.org/10.1787/97892 64210448-en

2. WHO (2016) WHO global urban ambient air pollution database (update 2016). https://www.who.int/phe/health_topics/outdoorair /databases/cities/en/. Accessed 22 Feb 2019

3. WHO Regional Officefor Europe, OECD (2015) Economic cost of the health impact of air pollution in Europe: clean air, health and wealth. WHO Regional Office for Europe, Copenhagen

4. Chen H, Kwong JC, Copes R, Tu K, Villeneuve PJ, Van Donkelaar A, Hystad P, Martin RV, Murray BJ, Jessiman B (2017) Living near major roads and the incidence of dementia, Parkinson's disease, and multiple sclerosis: a population-based cohort study. Lancet 389:718-726

5. Raz R, Roberts AL, Lyall K, Hart JE, Just AC, Laden F, Weisskopf MG (2015) Autism spectrum disorder and particulate matter air pollution before, during, and after pregnancy: a nested case-control analysis within the Nurses' Health Study II Cohort. Environ Health Perspect 123:264-270

6. Attademo L, Bernardini F, Garinella R, Compton MT (2017) Environmental pollution and risk of psychotic disorders: a review of the science to date. Schizophr Res 181:55-59

7. Oudin A, Braback L, Astrom DO, Stromgren M, Forsberg B (2016) Association between neighbourhood air pollution concentrations and dispensed medication for psychiatric disorders in a large longitudinal cohort of Swedish children and adolescents. BMJ Open 6:e010004

8. Power MC, Weisskopf MG, Alexeeff SE, Coull BA, Spiro A 3rd, Schwartz J (2011) Traffic-related air pollution and cognitive function in a cohort of older men. Environ Health Perspect 119:682-687 
9. Khan A, Plana-Ripoll O, Antonsen S, Brandt J, Geels C, Landecker H, Sullivan PF, Pedersen CB, Rzhetsky A (2019) Environmental pollution is associated with increased risk of psychiatric disorders in the US and Denmark. PLoS Biol 17:e3000353

10. Newbury JB, Arseneault L, Beevers S, Kitwiroon N, Roberts S, Pariante CM, Kelly FJ, Fisher HL (2019) Association of air pollution exposure with psychotic experiences during adolescence. JAMA Psychiatry 76:614-623

11. Carey IM, Anderson HR, Atkinson RW, Beevers SD, Cook DG, Strachan DP, Dajnak D, Gulliver J, Kelly FJ (2018) Are noise and air pollution related to the incidence of dementia? A cohort study in London, England. BMJ Open 8:e022404

12. Pedersen CB, Raaschou-Nielsen O, Hertel O, Mortensen PB (2004) Air pollution from traffic and schizophrenia risk. Schizophr Res 66:83-85

13. Kioumourtzoglou M, Power MC, Hart JE, Okereke OI, Coull BA, Laden F, Weisskopf MG (2017) The association between air pollution and onset of depression among middle-aged and older women. Am J Epidemiol 185:801-809

14. Power MC, Kioumourtzoglou MA, Hart JE, Okereke OI, Laden F, Weisskopf MG (2015) The relation between past exposure to fine particulate air pollution and prevalent anxiety: observational cohort study. BMJ 350:h1111

15. Block ML, Calderon-Garciduenas L (2009) Air pollution: mechanisms of neuroinflammation and CNS disease. Trends Neurosci 32:506-516

16. Prata J, Santos SG, Almeida MI, Coelho R, Barbosa MA (2017) Bridging Autism Spectrum Disorders and schizophrenia through inflammation and biomarkers-pre-clinical and clinical investigations. J Neuroinflamm 14:179

17. Maher BA, Ahmed IA, Karloukovski V, MacLaren DA, Foulds PG, Allsop D, Mann DM, Torres-Jardon R, Calderon-Garciduenas L (2016) Magnetite pollution nanoparticles in the human brain. Proc Natl Acad Sci USA 113:10797-10801

18. González-Maciel A, Reynoso-Robles R, Torres-Jardón R, Mukherjee PS, Calderón-Garcidueñas L (2017) Combustionderived nanoparticles in key brain target cells and organelles in young urbanites: culprit hidden in plain sight in Alzheimer's disease development. J Alzheimer's Dis 59(1):189-208

19. Calderón-Garcidueñas L, Mora-Tiscareño A, Ontiveros E, Gómez-Garza G, Barragán-Mejía G, Broadway J, Chapman S, Valencia-Salazar G, Jewells V, Maronpot RR, Henríquez-Roldán C, Pérez-Guillé B, Torres-Jardón R, Herrit L, Brooks D, OsnayaBrizuela N, Monroy ME, González-Maciel A, Reynoso-Robles R, Villarreal-Calderon R, Solt AC, Engle RW (2008) Air pollution, cognitive deficits and brain abnormalities: a pilot study with children and dogs. Brain Cogn. https://doi.org/10.1016/j.bandc .2008.04.008

20. de Prado BP, Mercader EMH, Pujol J, Sunyer J, Mortamais M (2018) The effects of air pollution on the brain: a review of studies interfacing environmental epidemiology and neuroimaging. Curr Environ Health Rep 5:351-364

21. Lewis AC, Carslaw DC, Kelly FJ (2015) Vehicle emissions: diesel pollution long under-reported. Nature 526:195

22. Bernardini F, Attademo L, Trezzi R, Gobbicchi C, Balducci P, Del Bello V, Menculini G, Pauselli L, Piselli M, Sciarma T (2019) Air pollutants and daily number of admissions to psychiatric emergency services: evidence for detrimental mental health effects of ozone. Epidemiol Psychiatr Sci 29:1-7

23. Buoli M, Grassi S, Caldiroli A, Carnevali GS, Mucci F, Iodice S, Cantone L, Pergoli L, Bollati V (2018) Is there a link between air pollution and mental disorders? Environ Int 118:154-168

24. Hatch SL, Frissa S, Verdecchia M, Stewart R, Fear NT, Reichenberg A, Morgan C, Kankulu B, Clark J, Gazard B (2011) Identifying socio-demographic and socioeconomic determinants of health inequalities in a diverse London community: the South East
London Community Health (SELCoH) study. BMC Public Health 11:861

25. Hatch S, Gazard B, Williams D, Frissa S, Goodwin L, Hotopf M, SELCoH Study Team (2016) Discrimination and common mental disorder among migrant and ethnic groups: findings from a South East London Community sample. Soc Psychiatry Psychiatr Epidemiol 51:689-701

26. Lewis G, Pelosi AJ, Araya R, Dunn G (1992) Measuring psychiatric disorder in the community: a standardized assessment for use by lay interviewers. Psychol Med 22:465-486

27. Kroenke K, Spitzer RL, Williams JB (2002) The PHQ-15: validity of a new measure for evaluating the severity of somatic symptoms. Psychosom Med 64:258-266

28. Ware JE Jr, Kosinski M, Keller SD (1996) A 12-Item Short-Form Health Survey: construction of scales and preliminary tests of reliability and validity. Med Care 34:220-233

29. Bebbington P, Nayani T (1995) The psychosis screening questionnaire. Int J Methods Psychiatr Res 5:11-19

30. Morgan C, Reininghaus U, Reichenberg A, Frissa S, SELCoH Study Team, Hotopf M, Hatch SL (2014) Adversity, cannabis use and psychotic experiences: evidence of cumulative and synergistic effects. Br J Psychiatry 204:346-353

31. Mudway IS, Dundas I, Wood HE, Marlin N, Jamaludin JB, Bremner SA, Cross L, Grieve A, Nanzer A, Barratt BM (2019) Impact of London's low emission zone on air quality and children's respiratory health: a sequential annual cross-sectional study. Lancet Public Health 4:e28-e40

32. Goodwin L, Gazard B, Aschan L, MacCrimmon S, Hotopf M, Hatch S (2017) Taking an intersectional approach to define latent classes of socioeconomic status, ethnicity and migration status for psychiatric epidemiological research. Epidemiol Psychiatr Sci 27(6):589-600

33. Babor TF, Higgins-Biddle JC, Saunders JB, Monteiro MG, World Health Organization (2001) AUDIT: the alcohol use disorders identification test: guidelines for use in primary health care. World Health Org, Geneva

34. Gulliver J, Morley D, Vienneau D, Fabbri F, Bell M, Goodman P, Beevers S, Dajnak D, Kelly FJ, Fecht D (2015) Development of an open-source road traffic noise model for exposure assessment. Environ Model Softw 74:183-193

35. Department of Communities and Local Government (2011) The English indices of deprivation 2010. https://www.gov.uk/gover nment/statistics/english-indices-of-deprivation-2010

36. Sterne JA, White IR, Carlin JB, Spratt M, Royston P, Kenward MG, Wood AM, Carpenter JR (2009) Multiple imputation for missing data in epidemiological and clinical research: potential and pitfalls. BMJ 338:b2393

37. Rabe-Hesketh S, Skrondal A, Pickles A (2002) Reliable estimation of gen- eralized linear mixed models using adaptive quadrature. Stata J 2(1):1-21

38. Smith RB, Fecht D, Gulliver J, Beevers SD, Dajnak D, Blangiardo M, Ghosh RE, Hansell AL, Kelly FJ, Anderson HR, Toledano MB (2017) Impact of London's road traffic air and noise pollution on birth weight: retrospective population based cohort study. BMJ 359:j5299

39. Shin J, Park JY, Choi J (2018) Long-term exposure to ambient air pollutants and mental health status: a nationwide population-based cross-sectional study. PLoS ONE 13:e0195607

40. Fecht D, Hansell AL, Morley D, Dajnak D, Vienneau D, Beevers S, Toledano MB, Kelly FJ, Anderson HR, Gulliver J (2016) Spatial and temporal associations of road traffic noise and air pollution in London: implications for epidemiological studies. Environ Int 88:235-242

41. Richards M, Hatch SL (2011) A life course approach to the development of mental skills. J Gerontol B Psychol Sci Soc Sci 66:i26-i35 
42. Dominici F, Peng RD, Barr CD, Bell ML (2010) Protecting human health from air pollution: shifting from a single-pollutant to a multipollutant approach. Epidemiology 21:187-194

43. Molitor J, Coker E, Jerrett M, Ritz B, Li A (2016) Part 3. Modeling of multipollutant profiles and spatially varying health effects with applications to indicators of adverse birth outcomes. Development of statistical methods for multipollutant research. Research report 183, Health Effects Institute, Boston, MA

44. Antonsen S, Mok PL, Webb RT, Mortensen PB, McGrath JJ, Agerbo E, Brandt J, Geels C, Christensen JH, Pedersen CB (2020) Exposure to air pollution during childhood and risk of developing schizophrenia: a national cohort study. Lancet Planet Health 4:e64-e73

45. Tong L, Li K, Zhou Q (2016) Season, sex and age as modifiers in the association of psychosis morbidity with air pollutants: a rising problem in a Chinese metropolis. Sci Total Environ 541:928-933

46. Liang Z, Xu C, Cao Y et al (2019) The association between shortterm ambient air pollution and daily outpatient visits for schizophrenia: a hospital-based study. Environ Pollut 244:102-108

47. WHO (2016) Ambient air pollution: a global assessment of exposure and burden of disease. Geneva, Switzerland: WHO; 2016. https://www.who.int/phe/publications/air-pollution-global-asses sment/en/. Accessed 18 June 2020

48. Mondelli V, Vernon AC, Turkheimer F, Dazzan P, Pariante CM (2017) Brain microglia in psychiatric disorders. Lancet Psychiatry 4:563

49. Heusinkveld HJ, Wahle T, Campbell A, Westerink RH, Tran L, Johnston H, Stone V, Cassee FR, Schins RP (2016) Neurodegenerative and neurological disorders by small inhaled particles. Neurotoxicology 56:94-106

50. Li W, Dorans KS, Wilker EH, Rice MB, Ljungman PL, Schwartz JD, Coull BA, Koutrakis P, Gold DR, Keaney JF Jr, Vasan RS, Benjamin EJ, Mittleman MA (2017) Short-term exposure to ambient air pollution and biomarkers of systemic inflammation: the Framingham Heart Study. Arterioscler Thromb Vasc Biol 37:1793-1800

51. Hassanvand MS, Naddafi K, Kashani H, Faridi S, Kunzli N, Nabizadeh R, Momeniha F, Gholampour A, Arhami M, Zare A (2017) Short-term effects of particle size fractions on circulating biomarkers of inflammation in a panel of elderly subjects and healthy young adults. Environ Pollut 223:695-704
52. Campbell A, Oldham M, Becaria A, Bondy SC, Meacher D, Sioutas C et al (2005) Particulate matter in polluted air may increase biomarkers of inflammation in mouse brain. Neurotoxicology 26:133-140

53. Saunders CR, Das SK, Ramesh A, Shockley DC, Mukherjee S (2006) Benzo(a)pyrene-induced acute neurotoxicity in the F-344 rat: role of oxidative stress. J Appl Toxicol 26:427-438

54. Calderón-Garcidueñas L, Azzarelli B, Acuna H, Garcia R, Gambling TM, Osnaya N, Monroy S, Del Tizapantzi MR, Carson JL, Villarreal-Calderon A, Rewcastle B (2002) Air pollution and Brain Damage. Toxicol Pathol 30(3):373-389

55. Oberdorster G, Utell MJ (2002) Ultrafine particles in the urban air: to the respiratory tract-and beyond? Environ Health Perspect 110:A440-A441

56. Liu Y, Ho RC-M, Mak A (2012) Interleukin (IL)-6, tumour necrosis factor alpha (TNF- $\alpha$ ) and soluble interleukin-2 receptors (sIL-2R) are elevated in patients with major depressive disorder: a meta-analysis and meta-regression. J Affect Disord 139(3):230-239. https://doi.org/10.1016/j.jad.2011.08.003 (PMID: 21872339)

57. Barron H, Hafizi S, Andreazza AC, Mizrahi R (2017) Neuroinflammation and oxidative stress in psychosis and psychosis risk. Int $\mathrm{J}$ Mol Sci. https://doi.org/10.3390/ijms18030651 (PMID: 28304340)

58. Block ML, Elder A, Auten RL, Bilbo SD, Chen H, Chen J, CorySlechta DA, Costa D, Diaz-Sanchez D, Dorman DC (2012) The outdoor air pollution and brain health workshop. Neurotoxicology 33:972-984

59. Gauderman WJ, Urman R, Avol E, Berhane K, McConnell R, Rappaport E, Chang R, Lurmann F, Gilliland F (2015) Association of improved air quality with lung development in children. $\mathrm{N}$ Engl J Med 372:905-913

60. Wei Y, Wang Y, Di Q et al (2019) Short term exposure to fine particulate matter and hospital admission risks and costs in the Medicare population: time stratified, case crossover study. BMJ 367:16258

61. Wu X, Nethery RC, Sabath BM, Braun D, Dominici F (2020) Exposure to air pollution and COVID-19 mortality in the United States. medRxiv. medRxiv 2020.04.05.20054502. https://doi. org/10.1101/2020.04.05.20054502

\section{Affiliations}

\section{loannis Bakolis ${ }^{1,2}$ - Ryan Hammoud ${ }^{3} \cdot$ Robert Stewart $^{4,5} \cdot$ Sean Beevers ${ }^{6} \cdot$ David Dajnak $^{6} \cdot$ Shirlee MacCrimmon $^{4}$. Matthew Broadbent ${ }^{5} \cdot$ Megan Pritchard $^{5} \cdot$ Narushige Shiode $^{7} \cdot$ Daniela Fecht $^{8} \cdot$ John Gulliver $^{9} \cdot$ Matthew Hotopf $^{4,5}$. Stephani L. Hatch ${ }^{4,5} \cdot \operatorname{lan}$ S. Mudway ${ }^{6,10}$}

1 Health Services and Population Research Department, Centre for Implementation Science, Institute of Psychiatry, Psychology and Neuroscience, King's College London, London, UK

2 Department of Biostatistics and Health Informatics, Institute of Psychiatry, Psychology and Neuroscience, King's College London, London, UK

3 Department of Psychosis Studies, Institute of Psychiatry, Psychology and Neuroscience King's College London, King's College London, London, UK

4 Department of Psychological Medicine, Institute of Psychiatry, Psychology and Neuroscience, King's College London, London, UK

5 NIHR Biomedical Research Centre for Mental Health at the South London and Maudsley NHS Foundation Trust, King's College London, London, UK, London, UK
6 MRC Centre for Environment and Health, School of Public Health, Environmental Research Group, Imperial College London, London, UK

7 Department of Geography, King's College London, London, UK

8 MRC Centre for Environment and Health, School of Public Health, Imperial College London, London, UK

9 Centre for Environmental Health and Sustainability, School of Geography, Geology and the Environment, University of Leicester, Leicester, UK

10 National Institute for Health Research, Health Protection Research Unit on Environmental Exposures and Health, Imperial College London, London, UK 